From the Departments of Thoracic/ Head and Neck Medical Oncology, Thoracic and Cardiovascular Surgery, and Pathology, The University of Texas M. D. Anderson Cancer Center, Houston, TX; and Section of Hematology/ Oncology, University of Chicago Medical Center, Chicago, IL.

Submitted August 28, 2008; accepted December 10, 2008; published online ahead of print at www.jco.org on March 2, 2009.

Authors' disclosures of potential conflicts of interest and author contributions are found at the end of this article.

Corresponding author: Anne S. Tsao, MD, Department of Thoracic/Head and Neck Medical Oncology, The University of Texas M. D. Anderson Cancer Center, 1515 Holcombe Blvd, Unit 432 Houston, TX 77030; e-mail: astsao@ mdanderson.org.

(c) 2009 by American Society of Clinical Oncology

0732-183X/09/2712-2081/\$20.00

DOI: $10.1200 / J C O .2008 .19 .8523$

\title{
Malignant Pleural Mesothelioma
}

Anne S. Tsao, Ignacio Wistuba, Jack A. Roth, and Hedy Lee Kindler

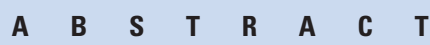

Malignant pleural mesothelioma (MPM) is a deadly disease that occurs in 2,000 to 3,000 people each year in the United States. Although MPM is an extremely difficult disease to treat, with the median overall survival ranging between 9 and 17 months regardless of stage, there has been significant progress over the last few years that has reshaped the clinical landscape. This article will provide a comprehensive discussion of the latest developments in the treatment of MPM. We will provide an update of the major clinical trials that impact mesothelioma treatment in the resectable and unresectable settings, discuss the impact of novel therapeutics, and provide perspective on where the clinical research in mesothelioma is moving. In addition, there are controversial issues, such as the role of extrapleural pneumonectomy, adjuvant radiotherapy, and use of intensity-modulated radiotherapy versus hemithoracic therapy that will also be addressed in this manuscript.

\section{J Clin Oncol 27:2081-2090. (C) 2009 by American Society of Clinical Oncology}

\section{INTRODUCTION}

Malignant pleural mesothelioma (MPM) is a deadly disease that occurs in 2,000 to 3,000 people each year in the United States. After the 1970s bans on asbestos were initiated, it was believed that the United States incidence of MPM would peak in 2004. ${ }^{1,2}$ However, MPM remains a serious problem as the worldwide incidence of the disease continues to increase; in Western Europe, more than 5,000 new cases per year are estimated to occur, with more than a quarter of a million deaths expected to occur over the next 40 years. ${ }^{3-5}$ In Japan, the peak incidence is predicted in 2025, and 103,000 deaths are anticipated over the next 40 years. ${ }^{5}$

MPM occurs predominantly in men (ratio of men to women, 5:1), and risk increases with age (median age at diagnosis is 72 years in the United States; range, 45 to 85 years). ${ }^{6,7}$ There are three main histologic subtypes of mesothelioma: epithelioid, biphasic, and sarcomatoid. Epithelioid tumors are most common and have a better prognosis than biphasic and sarcomatoid tumors. The major risk factor for MPM is occupational exposure to asbestos, ${ }^{8}$ often with development of the disease between 20 and 60 years later. ${ }^{9}$ Less frequently, prior radiation exposure and simian virus 40 have been suggested as causative agents in MPM.,10-13 Familial forms of MPM with autosomal dominant inheritance have been reported in the Cappadocia region of Turkey (Tuzkoy, Karain, and Sarihidir). 8,10,14

Currently, there are no approved screening modalities for the early detection of mesotheli- oma. However, two serum markers have recently been developed, serum mesothelin-related peptide and osteopontin. Serum mesothelin-related peptide, which is elevated in patients with epithelioid and biphasic MPM, may be predictive of disease recurrence after surgical resection. ${ }^{15,16}$ Osteopontin, a glycoprotein that binds integrin and CD44 receptors, may distinguish patients with MPM from those who have benign pleural changes resulting from asbestos exposure. ${ }^{17,18}$

MPM is an extremely difficult disease to treat, with the median overall survival ranging between 9 and 17 months, regardless of stage. Part of the difficulty in making progress in this disease type has been that there are few randomized controlled studies as a result of the small numbers of patients, problematic response measurements, variable staging of the disease between the trials (surgical staging $v$ radiographic staging), and histologic heterogeneity in the patients enrolled onto trials. However, despite these limitations, there have been developments over the last few years that may ultimately reshape the clinical landscape. ${ }^{19-21}$ This article will provide a comprehensive discussion of the latest progress in the treatment of MPM.

\section{RESECTABLE DISEASE}

\section{Surgery}

Surgical techniques used in treating patients with MPM include diagnostic video-assisted thoracoscopy, palliative pleurectomy/decortication (P/D), 
and extrapleural pneumonectomy (EPP). P/D consists of an open thoracotomy; removal of the parietal pleura, pleura over the mediastinum, pericardium, and diaphragm; and stripping of the visceral pleura for decortication. An EPP includes en bloc removal of tissues in the hemithorax, including the parietal and visceral pleura, involved lung, mediastinal lymph nodes, diaphragm, and pericardium. In most cancer centers, patients with significant cardiac comorbidities, sarcomatoid histology, mediastinal lymph nodes, and poor performance status are not considered candidates for EPP because they usually have a worse prognosis. ${ }^{22,23}$

Patients who receive $\mathrm{P} / \mathrm{D}$ alone often experience local recurrence as the first site of disease recurrence and, less frequently, distant recurrence; the local and distant recurrence rates are $64 \%$ to $72 \%$ and $10 \%$ to $36 \%$, respectively. This is in contrast to EPP alone, for which the distant recurrence rate is higher than that of local recurrence $(41 \%$ to $44 \% \vee 31 \%$ to $65 \%) .{ }^{22-24}$ Although EPP may alter the pattern of recurrence with less locoregional recurrence, it remains a surgical procedure that is associated with high morbidity, and its contribution toward overall survival benefit remains unclear. The 30-day operative mortality rate for EPP in experienced centers ranges between 3.4\% and $18 \%$, and the 2 -year survival rate is $10 \%$ to $37 \% .^{21,25-28}$

The choice of surgical resection technique at this time is controversial. Previously, it was assumed that EPP was the only treatment modality that could ensure long-term survival for patients with MPM because it macroscopically removed all gross disease. However, a complete R0 resection is theoretically impossible, because neither EPP nor $\mathrm{P} / \mathrm{D}$ will eliminate residual microscopic disease. It is therefore difficult to identify the role of EPP in MPM, because there are no definitive results available yet from randomized trials. At present, there is one ongoing phase III trial called the Mesothelioma and Radical Surgery trial that randomly assigns patients with MPM to either receive an EPP or a surgical debulking that is not an EPP. ${ }^{29}$ Patients in both arms of the trial may receive induction chemotherapy and or adjuvant radiotherapy, because it is believed that trimodality treatment can improve survival and locoregional control. ${ }^{20,30,31}$ Once this trial is completed, the role of EPP in MPM may be better defined.

Recently, from a large retrospective analysis $(n=663)$ comparing EPP with $\mathrm{P} / \mathrm{D}$, Flores et $\mathrm{al}^{30}$ reported that $\mathrm{P} / \mathrm{D}$ in combination with various multimodality therapies may also provide long-term survival benefit. This analysis showed that women; patients with earlier stage disease, epithelioid histology, treatment with multimodality therapy; and those who underwent P/D had better survival outcomes. ${ }^{30}$ After eliminating the operative deaths, multivariate analysis showed that EPP led to worse survival than $\mathrm{P} / \mathrm{D}$ (hazard ratio $[\mathrm{HR}]=1.4$;
$P<.001)$. Also, the choice of surgery did not affect survival outcomes for patients with either early-stage (I and II) or higher-stage (III and IV) disease. It therefore remains unclear which surgical resection may benefit a particular patient, and prospective randomized trials are needed to define this issue.

\section{Adjuvant Radiation Therapy}

In MPM, radiotherapy can be delivered either prophylactically to prevent tumor seeding at a surgically instrumented incision site (ie, chest tube sites) or for definitive intent to the entire hemithorax after surgical resection with EPP. Three small randomized studies compared prophylactic radiation with no radiation at chest tube drain or pleural biopsy sites. ${ }^{32-34}$ Two trials report no benefit; whereas one did; it therefore remains controversial whether prophylactic radiotherapy is warranted.

In the definitive setting, adjuvant hemithoracic radiotherapy (54 Gy) added to EPP improves local control, with a 13\% risk of local recurrence and $64 \%$ incidence of distant metastasis. ${ }^{31}$ To date, the only treatment modality that decreases the risk of local recurrence after surgical resection is radiotherapy. ${ }^{31}$ High-dose radiotherapy (54 Gy) with sequential chemotherapy was reported to improve locoregional control over moderate-dose radiotherapy (30 Gy to hemithorax, 40 Gy to mediastinum, and boost to $54 \mathrm{~Gy}$ in positive margins or nodes $).{ }^{35}$ However, this result $(\mathrm{n}=39)$ was not statistically significant, and the dose of radiotherapy did not predict for survival.

Alternative radiotherapy techniques, such as intensity-modulated radiation therapy, have early reports demonstrating a 95\% chance of disease control in the irradiated field and a locoregional control rate of $87 \% .^{21,36}$ However, intensity-modulated radiation therapy is not the standard of care, as there have been reports of high toxicity and morbidity (ie, fatal pneumonitis) associated with its use. ${ }^{37}$

\section{Chemotherapy}

In patients with resectable MPM, chemotherapy can be given in the neoadjuvant or adjuvant settings, concurrent with radiation. Table 1 lists the major neoadjuvant clinical trials.

Neoadjuvant chemotherapy. Owing to the small number of MPM candidates for EPP, few neoadjuvant trials have been successful. All neoadjuvant regimens studied to date include platinum doublets in single-arm trials, with the median survival ranging between 19 and 25 months (Table 1)..$^{20,38-41}$ The largest of these prospective trials $(\mathrm{n}=75)$ administered platinum and pemetrexed and reported preliminary results of a median time to progression of 13.1 months,

\begin{tabular}{|c|c|c|c|c|c|c|c|c|c|c|}
\hline $\begin{array}{l}\text { First } \\
\text { Author }\end{array}$ & $\begin{array}{l}\text { No. of } \\
\text { Patients }\end{array}$ & $\%$ Epithelioid & $\begin{array}{l}\text { pN2 } \\
(\%)\end{array}$ & Regimen & $\begin{array}{l}\text { No. of } \\
\text { Cycles }\end{array}$ & $\begin{array}{l}\text { Response } \\
\text { Rate (\%) }\end{array}$ & $\%$ EPP & $\begin{array}{c}\text { Completed Adjuvant } \\
\text { XRT (\%) }\end{array}$ & $\begin{array}{l}\text { Median PFS } \\
\text { (months) }\end{array}$ & $\begin{array}{l}\text { Median OS } \\
\text { (months) }\end{array}$ \\
\hline Weder $^{38}$ & 19 & 74 & 0 & Cisplatin plus gemcitabine & 3 & 32 & 84 & 68 & 16.5 & 23 \\
\hline Flores $^{39}$ & 19 & 74 & 37 & Cisplatin plus gemcitabine & 4 & 26 & 42 & 42 & NR & 19 \\
\hline Weder $^{40}$ & 61 & 69 & 23 & Cisplatin plus gemcitabine & 3 & NR & 61 & 59 & 13.5 & 19.8 \\
\hline $\operatorname{Rea}^{41}$ & 21 & 95 & 24 & Carboplatin plus gemcitabine & 4 & 33 & 81 & 71 & NR & 25.5 \\
\hline Krug $^{20}$ & 75 & 80 & 45 & Cisplatin plus pemetrexed & 4 & 29.3 & 67 & 56 & 13.1 & 16.6 \\
\hline
\end{tabular}


overall survival of 16.6 months, and 1-year overall survival rate of $67 \%$. $^{20}$ The response rate to induction chemotherapy was $29 \%$, with $67 \%$ of the patients $(n=50)$ undergoing EPP and only $56 \%$ proceeding to adjuvant radiotherapy. The subgroup analysis indicated that patients with a complete or partial response to neoadjuvant chemotherapy had a trend toward prolonged overall survival (29.1 $v 13.9$ months; $P=.076$ ). Because the efficacy of neoadjuvant chemotherapy remains unproven, a neoadjuvant trial at The University of Texas M. D. Anderson Cancer Center (Houston, TX) using dasatinib is currently underway and will provide maintenance dasatinib after surgery, adjuvant radiation, and adjuvant chemotherapy in patients with MPM with a response to induction therapy.

Adjuvant chemoradiotherapy. Adjuvant chemoradiotherapy is difficult to administer after EPP because of associated toxicities, and as such, there are few trials available to review. One of the largest series evaluated 183 patients who received EPP followed by carboplatin and paclitaxel for two cycles, then thoracic radiation therapy (50-Gy dose) with concurrent paclitaxel weekly, and then carboplatin and paclitaxel for two cycles. ${ }^{27,42}$ For the 176 patients who survived the EPP, the 2 -year-survival rate was 38\%, the 5-year-survival rate was $15 \%$, and the median overall survival was 19 months. ${ }^{42}$ Patients with epithelioid histology, negative resection margins, and no extrapleural lymph node metastasis had the best prognosis, with a median overall survival of 51 months $(P=.013){ }^{42}$ This series has since been updated to include 496 patients. The 418 patients who received EPP had a median overall survival of 18.9 months and a 5-year overall survival rate of $13.9 \% .^{25,43}$

\section{UNRESECTABLE DISEASE}

\section{Chemotherapy}

Historically, assessing clinical benefit in patients with unresectable MPM has been challenging. As guidelines, there are favorable clinical prognostic features, which include epithelioid histology, female sex, and no nodal metastasis; whereas patients with sarcomatoid histology, poor performance status, and elevated hematologic parameters have a worse prognosis. ${ }^{44,45}$ However, treatment response assessments are limited by the complexity of measuring the asymmetric tumor rind. A system called the modified Response Evaluation Criteria in Solid Tumors can be reliably used to assess tumor response ${ }^{46,47}$; however, these measurements do not always predict survival. ${ }^{48}$ The European Organisation for Research and Treatment of Cancer (EORTC) has therefore proposed that progression-free survival rates at 3, 4, 5, and 6 months be used as the primary end points in phase II trials to reflect the potential survival benefit of cytostatic agents. ${ }^{49}$

Before 2003, few chemotherapy agents had response rates higher than $20 \% .^{50}$ Ellis et $\mathrm{al}^{51}$ reviewed 119 trials (eight randomized, 111 noncomparative) and reported that combination chemotherapy had higher response rates than single agents. Platinum-containing regimens had higher response rates compared with non-platinumcontaining regimens, with cisplatin yielding better outcomes than carboplatin. Platinum agents combined with anthracyclines $(32.4 \%)$, gemcitabine, or irinotecan $(26.1 \%)$ had the highest response rates. When platinum agents were combined with immunomodulator effectors, such as interleukin or interferon, the response rate was $12 \%{ }^{51}$ These data do have limitations, as most MPM trials are single-arm phase II studies, owing to the small number of available patients.

\section{Front-Line Chemotherapy}

As MPM is more chemotherapy resistant than other tumor types, the Medical Research Council conducted a randomized phase III trial comparing active supportive care with two different chemotherapy regimens (mitomycin, vinblastine, and cisplatin or weekly vinorelbine) and reported that chemotherapy did not significantly improve survival over active supportive care. ${ }^{52}$ However, when analyzing the results from the single-agent vinorelbine arm, there was a trend toward survival that did not reach statistical significance, likely because the study was underpowered to determine this survival difference between the individual arms. Patients who received vinorelbine had a median progression-free survival of 6.2 months $(\mathrm{HR}=0.82$; $P=.114)$ and median overall survival of 9.5 months $(\mathrm{HR}=0.8$; $P=.08){ }^{52}$ This suggests that certain chemotherapy agents do improve survival for patients with MPM. In addition, subsequent randomized trials using newer agents such as pemetrexed and raltitrexed combined with platinum agents confirm the survival benefit over cisplatin alone. ${ }^{19,53}$ Table 2 lists the response rates to selected chemotherapy agents and regimens.

Platinum and antifolates. The combination of cisplatin $(75 \mathrm{mg} /$ $\left.\mathrm{m}^{2}\right)$ and pemetrexed $\left(500 \mathrm{mg} / \mathrm{m}^{2}\right)$ given every 3 weeks was established as a standard-of-care front-line regimen after the largest phase III trial conducted in patients $(n=456)$ with chemotherapy-naïve MPM demonstrated a survival improvement over cisplatin alone. ${ }^{19}$ The combination regimen had a $41.3 \%$ response rate, median time to progression of 5.7 months, and median overall survival of 12.1 months. Patient quality of life also improved rapidly — within the first three cycles of treatment — with statistically significant improvements often seen by week $15{ }^{58}$ This regimen is now the benchmark against which other front-line regimens are evaluated.

Other antifolates have been investigated, but they are less commonly used then pemetrexed. The EORTC reported that raltitrexed (3 $\left.\mathrm{mg} / \mathrm{m}^{2}\right)$ combined with cisplatin $\left(80 \mathrm{mg} / \mathrm{m}^{2}\right)$ improved the overall response rate compared with cisplatin alone $(24 \% v 14 \% ; P=.06)$, with no reported difference in quality of life. ${ }^{53}$ However, although the response rate was not statistically significant, the median overall survival in patients receiving raltitrexed plus cisplatin was increased to 11.4 months, and the 1-year survival rate was increased to $46 \%$ $(\mathrm{HR}=0.76 ; P=.048){ }^{53}$

Other combination and maintenance regimens under investigation have substituted carboplatin for cisplatin. Carboplatin plus pemetrexed yields response rates of $6 \%$ to $22 \%$, median time to progression of 6.5 to 7 months, and median overall survival of 9.3 to 12.7 months. ${ }^{56,57,59,60}$ The International Extended Access Program ${ }^{61}$ trial conducted in 1,704 patients with chemotherapy-naïve or pretreated MPM found that cisplatin plus pemetrexed and carboplatin plus pemetrexed had similar response rates (26.3\% and $21.7 \%)$, time to progression ( 7 months and 6.9 months), and 1-year overall survival rates (63.1\% and 64\%). In the International Extended Access Program, single-agent pemetrexed achieves response rates of 10.5\% and $12.1 \%$ for chemotherapy-naïve and pretreated patients with MPM, respectively. ${ }^{62}$

The concept of maintenance or continued therapy after frontline treatment remains investigational. One small study has shown the feasibility of maintenance pemetrexed and demonstrated that responses could occur even after six cycles of treatment. ${ }^{63}$ However, the role of maintenance therapy requires additional examination in larger prospective trials before being implemented as 


\begin{tabular}{|c|c|c|c|c|c|}
\hline Chemotherapy Agents & No. of Trials & No. of Patients & Response Rate (\%) & $\begin{array}{l}\text { Median PFS } \\
\text { (months) }\end{array}$ & $\begin{array}{l}\text { Median OS } \\
\text { (months) }\end{array}$ \\
\hline \multicolumn{6}{|l|}{ Single agent } \\
\hline Cisplatin & 5 & 108 & 20 & NR (5 trials NR) & 5-11 (1 trial NR) \\
\hline Cisplatint & 2 & 346 & 15.7 & $3.9-4$ & $8.8-9.3$ \\
\hline Carboplatin & 3 & 89 & 10.1 & 2.8 (2 trials $N R)$ & 7.1-8 (1 trial NR) \\
\hline \multicolumn{6}{|l|}{ Pemetrexed } \\
\hline Chemotherapy-naïve & $1 \neq$ & 319 & 10.5 & 6 & 14.1 \\
\hline Pretreated & $1 \neq$ & 493 & 12.1 & 4.9 & $N R$ \\
\hline Pretreated & 2 & 214 & 13.1 & 3.6 (1 trial NR) & $4.1-8.4$ \\
\hline Vinflunine & 1 & 67 & 13.8 & 3.2 & 10.8 \\
\hline \multicolumn{6}{|l|}{ Vinorelbine } \\
\hline Chemotherapy-naïve & 2 & 165 & 18.8 & 6.2 (1 trial NR) & $9.5-10.6$ \\
\hline Pretreated & 1 & 63 & 16 & NR & 9.6 \\
\hline Antimetabolites & 8 & 319 & 9.0 & 1.5-5.2 (4 trials NR) & 4.9-11 (1 trial NR) \\
\hline Gemcitabine & 3 & 72 & 6.7 & 1.7 (2 trials NR) & 4.7-8 (1 trial NR) \\
\hline Anthracyclines or mitoxantrone & 10 & 319 & 6.1 & 5 (8 trials NR) & 4.5-17 (2 trials NR) \\
\hline Taxanes & 4 & 111 & 5.1 & $2.2-3.5$ (1 trial NR) & $4-12.4$ \\
\hline Topoisomerase inhibitors & 4 & 117 & 4.9 & 2.3 (3 trials NR) & 7.3-17 \\
\hline Alkylating agents & 7 & 194 & 4.6 & 2.5 (7 trials NR) & 6.5-10 (1 trial NR) \\
\hline Other & 12 & 376 & 4.0 & 2.1-3.4 (6 trials NR) & 5-13.2 (4 trials NR) \\
\hline \multicolumn{6}{|l|}{ Combination therapies } \\
\hline Cisplatin plus pemetrexed & 1 & 226 & 41 & 5.7 & 12.1 \\
\hline Cisplatin plus pemetrexed & $1 \neq$ & 843 & 26.3 & 7 & NR (1-year OS 63.1\%) \\
\hline Carboplatin plus pemetrexed & $1 \neq$ & 861 & 21.7 & 6.9 & NR (1-year OS 64\%) \\
\hline Carboplatin plus pemetrexed & $2 \xi$ & 178 & 21.3 & $6.5-8$ & $12.7-14$ \\
\hline Cisplatin plus raltitrexed & 1 & 126 & 24 & 5.3 & 11.4 \\
\hline Cisplatin plus gemcitabine & 5 & 184 & 25 & $6-8$ & $9.6-13$ \\
\hline Carboplatin plus gemcitabine & 2 & 70 & 24.3 & $10(1$ trial NR) & $10.8-16.5$ \\
\hline Cisplatin plus vinorelbine & 1 & 54 & 29.6 & 7.2 & 16.8 \\
\hline Platinum-based & 19 & 790 & 24.9 & $2.7-10$ (9 trials NR) & 6-19.2 (3 trials NR) \\
\hline Cisplatin plus anthracycline & 6 & 151 & 28.5 & 4.8 (5 trials NR) & 8.8-15 (1 trial NR) \\
\hline Cisplatin, nonanthracycline & 20 & 547 & 23.2 & $2.7-12(5$ trials NR) & 6.4-19.2 (3 trials NR) \\
\hline Cisplatin, mitomycin, vinblastine & 2 & 176 & 13 & 5.1 (1 trial NR) & $6-7.8$ \\
\hline Anthracycline, nonplatinum & 8 & 213 & 11.3 & 2.3-6.3 (6 trials NR) & 5.7-11 (1 trial NR) \\
\hline Nonplatinum, nonanthracycline & 5 & 172 & 15.7 & 4.3-7 (2 trials NR) & 8-13.5 (1 trial NR) \\
\hline \multicolumn{6}{|c|}{$\begin{array}{l}\text { Abbreviations: MPM, malignant pleural mesothelioma; PFS, progression-free survival; OS, overall survival; NR, not reported. } \\
{ }^{*} \text { Data were originally published in Berghmans et al }{ }^{54} \text { and adapted from Fennell et al. }{ }^{55} \\
\text { tData from the cisplatin control arms in the phase } \mathrm{III} \text { trials of Vogelzang et al }{ }^{19} \text { and van Meerbeeck et al. }{ }^{53} \\
\text { fInternational Expanded Access Program. } \\
\text { §Phase II trials of Ceresoli et al }{ }^{56} \text { and Castagneto et al. }{ }^{57}\end{array}$} \\
\hline
\end{tabular}

common practice. The Cancer and Leukemia Group B (CALGB) is planning a randomized trial to study maintenance therapy.

Additional front-line chemotherapy agents. Gemcitabine as a single agent has response rates between $0 \%$ and $31 \%{ }^{64}$; combining gemcitabine with cisplatin leads to response rates between $12 \%$ and $48 \%$ and median overall survival times of 9.4 to 13 months. ${ }^{65-69}$ The efficacy of a carboplatin plus gemcitabine regimen has also been reported, with a 1-year survival rate of $53 \%$ and time to progression of 40 weeks. ${ }^{70}$ Lee et $\mathrm{al}^{71}$ recently presented a retrospective Canadian series comparing platinum plus gemcitabine $(\mathrm{n}=38)$ with platinum plus pemetrexed $(n=34)$ and reported no difference in overall survival. An ongoing Eastern Cooperative Oncology Group trial in patients with good performance status is comparing carboplatin plus pemetrexed to gemcitabine plus pemetrexed. Janne et $\mathrm{al}^{72}$ recently reported a phase II trial in chemotherapy-naïve patients with MPM using two different schedules of pemetrexed and gemcitabine and reported a $17 \%$ to $26 \%$ response rate, and median survival of 8.08 to 10.12 months.

Previously, vinorelbine was the only vinca alkaloid that had single-agent activity in MPM, with response rates of $24 \%$ and median overall survival of 10.6 months. ${ }^{73}$ In one front-line trial $(\mathrm{n}=54)$, cisplatin added to vinorelbine improved the response rate to $29.6 \%$, median time to progression to 7.2 months, and overall survival to 16.8 months. ${ }^{74}$ However, the newest vinca alkaloid vinflunine, has shown similar efficacy in chemotherapy-naïve patients. Vinflunine $\left(320 \mathrm{mg} / \mathrm{m}^{2}\right)$ was given intravenously every 3 weeks to 67 patients with MPM, with a $13.8 \%$ response rate, a median progression-free survival of 3.2 months, and a median overall survival of 10.8 months. ${ }^{75}$

The Japanese have conducted several irinotecan-based clinical trials for patients with unresectable MPM. One pilot trial studied a triplet regimen of irinotecan and cisplatin followed by doxorubicin; 
the overall response rate was $36 \% .{ }^{76}$ A phase II trial used methotrexate, irinotecan, and doxorubicin; a 21\% partial response rate was reported, and the rate in the chemotherapy-naïve patients was $24 \% .{ }^{77}$ Although these triplet regimens showed tolerability and efficacy, irinotecan has not been developed for MPM in the United States. In the only US trial of irinotecan for MPM, CALGB studied single-agent irinotecan (125 $\mathrm{mg} / \mathrm{m}^{2}$ weekly for 4 of 6 weeks) in chemotherapy-naïve patients; the regimen had a $0 \%$ response rate and substantial toxicity. ${ }^{78}$ It is therefore likely that irinotecan-based regimens will remain geographically sponsored.

\section{Second-Line Chemotherapy}

At this time, there is no widely approved salvage regimen used for MPM. However, there is growing evidence that if pemetrexed is not given in the front-line setting, it should be administered in the salvage setting, either alone or in combination with platinum agents. ${ }^{79,80}$ Jassem et $\mathrm{al}^{81}$ conducted a phase III trial comparing second-line pemetrexed with best supportive care and reported that pemetrexed improved tumor response and progression-free survival but did not improve overall survival for unselected patients. The subgroup analysis demonstrated that patients who had responded to front-line chemotherapy had a trend toward longer overall survival with second-line pemetrexed. Gemcitabine plus vinorelbine was also found to have some efficacy as a salvage regimen in 28 patients who had failed to respond to pemetrexed-based chemotherapy. ${ }^{82}$ The response rate was $7.4 \%$, with stabilization of disease in an additional $37 \%$ of patients and a median time to progression of 2.8 months. Single-agent vinorelbine has also been evaluated in a phase II trial $(n=63)$, with a reported response rate of $16 \%$ and overall survival of 9.6 months. ${ }^{83}$

\section{Biologic Therapy}

Novel biologic therapies that have been successful against other solid tumors have also begun to be studied in MPM. To date, despite preclinical data demonstrating overexpression of epidermal growth factor receptor and platelet-derived growth factor receptor (PDGFR) on MPM tumor cells, clinical trials have shown no significant benefit from using single-agent inhibitors of the epidermal growth factor receptor (gefitinib or erlotinib) ${ }^{84,85}$ or of the PDGFR (imatinib mesylate) ${ }^{86-88}$ However, many new targets and biologic agents may have potential in the treatment of this disease (Table 3 ).

Antiangiogenic agents. Angiogenic inhibition with the monoclonal antibody bevacizumab provides a survival benefit in colorectal carcinoma and non-small-cell lung cancer. Patients with MPM have high levels of plasma vascular endothelial growth factor (VEGF), and as in lung cancer, higher levels of serum VEGF are correlated with a worse prognosis. ${ }^{101}$ However, a front-line phase II randomized trial $(\mathrm{n}=115)$ using cisplatin and gemcitabine with or without bevacizumab did not show an improvement in response rate nor survival with the addition of bevacizumab. ${ }^{89}$ A subgroup analysis noted that higher baseline plasma VEGF levels were correlated with a shorter progression-free and overall survival $(P=.02 ; P=.0066)$ and that patients with VEGF levels less than the median had longer progression-free and overall survival when treated with bevacizumab. This suggests that antiangiogenic therapy could benefit some patients with MPM; and several ongoing MPM studies with bevacizumab may further define which patients should receive antiangiogenic treatment. One such trial is a front-line study of cisplatin, pemetrexed, and bevacizumab. In the salvage setting, a small bevacizumab plus erlotinib trial $(n=24)$ recently reported no radiographic responses, with

\begin{tabular}{|c|c|c|c|c|c|c|}
\hline Target & Agent & Trial Phase & No. of Patients & $\mathrm{RR}(\%)$ & Median PFS (months) & Median OS (months) \\
\hline \multirow[t]{2}{*}{ EGFR } & Gefitinib 500 mg 84 & II & 43 & 4 & 2.6 & 6.8 \\
\hline & Erlotinib $^{85}$ & II & 63 & 0 & 2 & 10 \\
\hline \multirow[t]{2}{*}{ PDGFR, c-Kit } & Imatinib mesylate 800 mg 88 & II & 29 & 0 & $N R^{*}$ & NR \\
\hline & Imatinib mesylate $400-800$ mg ${ }^{86}$ & II & 25 & 0 & 2.1 & 13.3 \\
\hline VEGF & $\begin{array}{l}\text { Cisplatin/gemcitabine/bevacizumab } \\
\text { versus cisplatin/gemcitabine }\end{array}$ & II & 115 & $25 \vee 22 ; P=.88$ & $6.9 \vee 6.0 ; 15.6 \vee 14.7 ; P=.91$ & \\
\hline Flk-1/KDR & Semaxinib 90,91 & II & 23 & 11 & NR & 12.3 \\
\hline $\begin{array}{l}\text { VEGF, TNF- } \alpha \\
\text { bFGF }\end{array}$ & Thalidomide $200-400$ mg 92,93 & II & 40 & $\begin{array}{l}27.5 \text { (stable disease } \\
\text { at } 6 \text { months) } \dagger\end{array}$ & & 7.6 \\
\hline $\begin{array}{l}\text { VEGFR-1, -2, -3 } \\
\text { PDGFR, } \\
\text { c-Kit }\end{array}$ & Vatalanib ${ }^{94}$ & II & 47 & 11 & 4.1 & 10 \\
\hline $\begin{array}{l}\text { VEGFR-2 } \\
\text { PDGFRb, } \\
\text { Raf }\end{array}$ & Sorafenib ${ }^{95}$ & II & 51 & 4.4 & 3.7 & 10.7 \\
\hline $\begin{array}{c}\text { VEGFR-1, }-2,-3, \\
\text { PDGFR }\end{array}$ & Sunitinib 96 & II & 22 & 15 & 3.5 & 5.9 \\
\hline $\begin{array}{c}\text { RET, c-Kit, Flt- } \\
\text { 3tRNA }\end{array}$ & Ranpirnase ${ }^{97}$ & II & 105 & 5 & 3.4 & 6 \\
\hline tRNA & Ranpirnase versus doxorubicin 98,99 & III & 154 & NR & NR & $8.4 \vee 8.2 ; P=\mathrm{NS}$ \\
\hline $\begin{array}{l}\text { Histone } \\
\quad \text { deacetylase }\end{array}$ & $\begin{array}{l}\text { Vorinostat }{ }^{100} 300-400 \mathrm{mg} \text { BID } \times 3 \\
\text { d/wk }\end{array}$ & I & $10 \ddagger$ & 20 & NR & NR \\
\hline \multicolumn{7}{|c|}{$\begin{array}{l}\text { Abbreviations: RR, response rate; PFS, progression-free survival; OS, overall survival; EGFR, epidermal growth factor receptor; PDGFR, platelet-derived growth } \\
\text { factor receptor; NR, not reported; VEGF, vascular endothelial growth factor; TNF- } \alpha \text {, tumor necrosis factor } \alpha \text {; VEGFR, vascular endothelial growth factor receptor; NS, } \\
\text { not significant; BID, twice per day. } \\
\text { *Four patients had stable disease } \geq 3 \text { months. } \\
\text { †The primary end point on this trial was the rate of disease stabilization at } 6 \text { months. } \\
\text { †Thirteen patients were enrolled; intent-to-treat population yielded a } 15 \% \text { response rate. }\end{array}$} \\
\hline
\end{tabular}


a median time to progression of 2.2 months and median overall survival of 5.8 months. ${ }^{102}$

It is possible that VEGF receptor (VEGFR) tyrosine kinase inhibitors or concomitant inhibition of other tumor or angiogenesis targets will be needed to achieve the greatest antitumor effect for MPM. Several oral multikinase inhibitors that include VEGF/VEGFR pathway inhibition have been investigated in MPM. SU5416, or semaxanib (also targeting Flk-1/KDR), and thalidomide have been reported to produce clinical activity. ${ }^{90-92}$ Thalidomide as a single agent has been reported to achieve disease stabilization in $25 \%$ of patients for more than 6 months ${ }^{93}$ and is under investigation in an international trial, with patients with MPM receiving four cycles of platinum plus pemetrexed followed by thalidomide or best supportive care. In one phase II trial, vatalanib (targeting VEGFR-1, -2, and -3; PDGFR; and c-Kit) had an $11 \%$ response rate, a $66 \%$ stable-disease rate, median progression-free survival of 4.1 months, and median overall survival of 10 months. ${ }^{94}$ Sunitinib (targeting VEGFR, PDGFR, c-Kit, and Flt-3) has been evaluated in a phase II single-arm trial in patients who had experienced treatment failure with one platinum plus pemetrexed regimen. ${ }^{96}$ Of 22 assessable patients, there was a $15 \%$ partial response rate and 55\% stable disease rate by modified Response Evaluation Criteria in Solid Tumors. In patients without a talc pleurodesis, 10 were evaluated by $\left[{ }^{18} \mathrm{~F}\right]$ fluorodeoxyglucose positron emission tomography and a 30\% metabolic response (defined as a decrease in standardized uptake value levels) was seen. The median overall survival was 5.9 months, and median time to progression was 3.5 months. There was one treatment-related death attributed to pulmonary infiltrates and respiratory failure. A phase II trial (CALGB 30307) using sorafenib (targeting VEGFR-2, PDGFR, and Raf) at $400 \mathrm{mg}$ twice daily for MPM that was chemotherapy-naïve or previously treated with pemetrexed found grade 3 to 4 adverse effects that included fatigue in $25 \%$ of patients and hand-foot syndrome in $13 \% .^{95,103}$ The overall response rate was only $4.4 \%$, with a $38.8 \%$ disease-stabilization rate, median failure-free survival of 4.1 months, and median overall survival of 10.4 months. Chemotherapy-naïve patients had worse survival outcomes than the previously treated patients.

Other ongoing antiangiogenic agents in clinical trials include AZD2171 (targeting KDR, Flt-1 and -4, and PDGFR) in pretreated patients (Southwest Oncology Group) and cisplatin, pemetrexed, and AZD2171 (Southwest Oncology Group) in chemotherapy-naïve patients; sunitinib (targeting VEGFR, PDGFR- $\beta$, c-Kit, and Flt-3) in both front-line and salvage therapy settings (National Cancer Institute of Canada); and pazopanib, or GW786034 (targeting VEGFR-1, -2, and -3 and PDGFR) by the North Central Cancer Treatment Group. Although imatinib mesylate (targeting PDGFR- $\beta$, c-Kit, and BCR$\mathrm{Abl}$ ) as a single agent did not demonstrate activity in MPM, combination regimens with cisplatin plus pemetrexed in chemotherapy-naïve patients (M. D. Anderson Cancer Center) and with gemcitabine in pretreated patients (Gruppo Italiano Mesotelioma) are underway. ${ }^{104,105}$

Ribonuclease inhibitors. Ranpirnase specifically targets tumor cell tRNA and inhibits protein synthesis, resulting in cell cycle arrest at the $G_{1}$ phase. The adverse effect profile includes hypersensitivity, renal toxicity (proteinuria, azotemia), fatigue, and peripheral edema. Single-agent ranpirnase in a phase II MPM trial resulted in a 5\% response rate, a $43 \%$ stable disease rate, and a median overall survival of 6 months. ${ }^{97}$ A phase III trial $(\mathrm{n}=105)$ compared ranpirnase $(480$ $\mu \mathrm{g} / \mathrm{m}^{2}$ weekly) with doxorubicin $\left(60 \mathrm{mg} / \mathrm{m}^{2}\right.$ every 3 weeks $)$ and showed no difference in overall survival in the intent-to-treat analysis.
However, patients with CALGB prognostic groups 1 to 4 and EORTC risk criteria had a 2-month survival benefit when treated with ranpirnase over doxorubicin. ${ }^{98,99,106,107}$ A large international phase III trial (P30-302) comparing doxorubicin with the combination of doxorubicin and ranpirnase is ongoing (Table 3 ).

Histone deacetylase inhibitors. Histone acetylation regulates gene expression by allowing transcription factor access to genomic DNA. Deacetylation of histones leads to cell cycle progression and unchecked growth. Histone deacetylase inhibitors (HDACIs) are agents that prevent deacetylation and reinstate control over the cell cycle. Preclinical studies have shown that HDACIs inhibit cell cycle progression and/or induce tumor apoptosis. However, the exact antitumor mechanism of HDACIs is unknown, although caspase and bcl-xL may be involved. ${ }^{108,109}$ It is also believed that the antitumor effect of HDACIs may result from targeting nonhistone proteins, such as $\alpha$-tubulin, p53, heat shock protein 90 , and Ku70. ${ }^{110}$

Suberoylanilide hydroxamic acid (SAHA), or vorinostat, an oral HDACI, was studied in an early phase I trial that included 13 patients with mesothelioma (12 patients were previously treated). Single-agent SAHA given at $300 \mathrm{mg}$ or $400 \mathrm{mg}$ twice daily for 3 consecutive days per week yielded two partial responses in this small number of patients. ${ }^{100}$ The main toxicities were fatigue, anorexia, dehydration, nausea/vomiting, and diarrhea. An ongoing randomized, placebo-controlled, phase III trial of SAHA plans to accrue 660 patients with MPM for whom one or two prior therapies have failed (Table 3). Belinostat, also called PDX101, is an additional HDACI under investigation. It is a reversible hydroxamic acid, as is vorinostat.

Proteasome inhibitors. Proteasome complexes process ubiquitinated proteins and facilitate protein degradation. When proteasome activity is inhibited, nuclear factor $-\kappa \mathrm{B}$ production is also inhibited, and tumor cells undergo apoptosis. Preclinical studies in cell lines and murine xenograft models showed antitumor activity against MPM, ${ }^{111,112}$ and two European trials are underway using single-agent bortezomib (All Ireland Cooperative Oncology Research Group/ Gruppo Italiano Mesotelioma) and the combination of cisplatin and bortezomib (EORTC). ${ }^{111}$

Gene therapy. Early work with gene therapy used adenovirus vectors containing the herpesvirus thymidine kinase (Ad-HSVtk) suicide gene administered intrapleurally followed by intravenous ganciclovir. ${ }^{113,114}$ The premise for this work was to transduce viral thymidine kinase into the cancer cells and then administer the antiviral agent ganciclovir to selectively kill the tumor cells. Ganciclovir is metabolized to cytotoxic ganciclovir triphosphates by the thymidine kinase gene, which can potentially diffuse through the tumor and kill cells that are expressing the transgene. ${ }^{114}$ In addition to the direct anticancer effect, it was also presumed that an adenoviral-induced inflammatory response would stimulate the host immune system to attack the cancer cells. ${ }^{115}$ A phase I trial was therefore conducted using intrapleural Ad-HSVtk followed by 2 weeks of ganciclovir in 21 previously untreated patients with MPM. ${ }^{116}$ This trial demonstrated feasibility, with 11 of 20 assessable patients having transfer of the HSVtk gene into superficial tumor layers and two patients reporting long-term survival over 6.5 years. ${ }^{117}$ Analysis of these data suggested that the antitumor effect was more likely related to the immune modulatory effect from the Ad-HSVtk and ganciclovir rather than the direct anticancer effect for which it was originally designed. Therefore, a clinical trial using an adenoviral vector containing an immune stimulant interferon beta (IFN- $\beta$ ) was undertaken. This phase I trial injected adenoviral human 
interferon beta intrapleurally into 10 patients (seven had mesothelioma) and demonstrated successful gene transfer in seven patients. Three of the seven patients with mesothelioma had disease stability at 60 days. ${ }^{115}$ The main toxicities seen in the trial were transient hypoxia and reversible liver function value elevations. ${ }^{115}$ Further studies using the strategy of gene therapy and immune modulation are ongoing.

Other targets and agents. In patients with MPM, activated Src kinase may be a potential therapeutic target as studies of archival tumor tissue show that overexpression of activated Src kinase protein (phosphorylated Src $\mathrm{Y}^{419}$ ) is correlated with more advanced MPM disease and that preclinical studies with dasatinib, a multitargeted Src tyrosine kinase inhibitor, can lead to MPM cell cycle arrest, apoptosis, and impair the ability of the tumor cell to migrate and invade. ${ }^{118}$ Dasatinib is currently under investigation in clinical trials for the neoadjuvant setting (M. D. Anderson) and also as a second-line agent through a phase II trial sponsored by CALGB. Three antimesothelin agents are currently in clinical trials for mesothelioma: SS1P (an immunotoxin), Morab009 (an antimesothelin monoclonal antibody) and CRS-207(a Listeria monocytogene mesothelin vaccine). ${ }^{119,120}$ Both SS1P and Morab009 have completed single-agent trials and are now being investigated in phase I/II trials in combination with cisplatin and pemetrexed; CRS-207 is being evaluated as a single agent in phase I trials. Potential future targets for MPM therapy include the insulin-growth factor pathway, MEK pathway, and the PI3K/AKT pathways. ${ }^{121-123}$ Vaccines are also under investigation; the Memorial Sloan-Kettering Cancer Center recently reported results from a pilot trial of a Wilms' tumor 1 peptide vaccine, which demonstrated some activity against MPM. ${ }^{124}$ An adjuvant clinical trial using the Wilms' tumor 1 vaccine is currently under development.

In conclusion, at this time, surgical resection and adjuvant radiation therapy remain the mainstay of treatment for patients with resectable MPM. There is substantial evidence that systemic treatment is also necessary, as improvements in local control have been accompanied by increased rates of distant metastasis. Unfortunately, the optimal multimodality management of these patients remains unclear. Therefore, the use of systemic chemotherapy (neoadjuvant, intrapleural, and adjuvant) remains experimental, and it is encouraged that systemic treatment be administered in the setting of clinical trials.

For the patient with unresectable MPM, the antifolates or gemcitabine, given in combination with a platinum agent, have made the greatest clinical impact to date. Further progress is needed, however, and enrollment of patients with MPM onto clinical trials of novel therapeutic agents should be a priority. In addition to identifying new therapeutic targets, key issues that deserve further investigation include understanding the role of immune modulation, determining whether maintenance therapy should be used after front-line chemotherapy, distinguishing the genomic profiles between the histologic subtypes to ascertain whether they should be treated differently, identifying more accurate means of measuring clinical response, and validating surrogate blood-based markers for response. New strategies and target pathways under investigation will hopefully provide better therapeutic options for patients with MPM in the future.

\section{AUTHORS' DISCLOSURES OF POTENTIAL CONFLICTS} OF INTEREST

The author(s) indicated no potential conflicts of interest.

\section{AUTHOR CONTRIBUTIONS}

Conception and design: Anne S. Tsao, Ignacio Wistuba, Jack A. Roth, Hedy Lee Kindler

Administrative support: Anne S. Tsao, Hedy Lee Kindler

Provision of study materials or patients: Anne S. Tsao, Hedy Lee

Kindler

Collection and assembly of data: Anne S. Tsao, Ignacio Wistuba, Jack A. Roth, Hedy Lee Kindler

Data analysis and interpretation: Anne S. Tsao, Ignacio Wistuba, Jack A. Roth, Hedy Lee Kindler

Manuscript writing: Anne S. Tsao, Ignacio Wistuba, Jack A. Roth,

Hedy Lee Kindler

Final approval of manuscript: Anne S. Tsao, Ignacio Wistuba, Jack A. Roth, Hedy Lee Kindler

\section{REFERENCES}

1. Weill $H$, Hughes JM, Churg AM: Changing trends in US mesothelioma incidence. Occup Environ Med 61:438-441, 2004

2. Price B: Analysis of current trends in United States mesothelioma incidence. Am J Epidemiol 145:211-218, 1997

3. Peto J, Decarli A, La Vecchia C, et al: The European mesothelioma epidemic. Br J Cancer 79: 666-672, 1999

4. Levin SM, Herbert R, Moline J: Heath Effects among World Trade Center Responders. Lung Cancer 54:S10, 2006 (suppl; abstr 36)

5. Robinson BW, Lake RA: Advances in malignant mesothelioma. N Engl J Med 353:1591-1603, 2005

6. Larson T, Melnikova N, Davis SI, et al: Incidence and descriptive epidemiology of mesothelioma in the United States, 1999-2002. Int J Occup Environ Health 13:398-403, 2007

7. National Institute for Occupational Safety and Health: Occupational Respiratory Disease Surveillance: National Statistics, Work-Related Lung Disease Surveillance Report. Atlanta, GA, United
States Centers for Disease Control and Prevention, National Institute for Occupational Safety and Health, 2002

8. Carbone M, Kratzke RA, Testa JR: The pathogenesis of mesothelioma. Semin Oncol 29:217, 2002

9. Lanphear BP, Buncher CR: Latent period for malignant mesothelioma of occupational origin. $J$ Occup Med 34:718-721, 1992

10. Dogan AU, Baris YI, Dogan M, et al: Genetic predisposition to fiber carcinogenesis causes a mesothelioma epidemic in Turkey. Cancer Res 66: 5063-5068, 2006

11. Carbone M, Pass HI, Rizzo P, et al: Simian virus 40-like DNA sequences in human pleural mesothelioma. Oncogene 9:1781-1790, 1994

12. De Luca A, Baldi A, Esposito V, et al: The retinoblastoma gene family $\mathrm{pRb} / \mathrm{p} 105, \mathrm{p} 107, \mathrm{pRb} 2 /$ p130 and simian virus-40 large T-antigen in human mesotheliomas. Nat Med 3:913-916, 1997

13. Testa JR, Carbone M, Hirvonen A, et al: A multi-institutional study confirms the presence and expression of simian virus 40 in human malignant mesotheliomas. Cancer Res 58:4505-4509, 1998

14. Roushdy-Hammady I, Siegel J, Emri S, et al: Genetic-susceptibility factor and malignant me- sothelioma in the Cappadocian region of Turkey. Lancet 357:444-445, 2001

15. Robinson BW, Creaney J, Lake $R$, et al: Soluble mesothelin-related protein: A blood test for mesothelioma. Lung Cancer 49:S109-S111, 2005 (suppl 1)

16. Robinson BW, Creaney J, Lake R, et al: Mesothelin-family proteins and diagnosis of mesothelioma. Lancet 362:1612-1616, 2003

17. Pass HI, Lott D, Lonardo F, et al: Asbestos exposure, pleural mesothelioma, and serum osteopontin levels. N Engl J Med 353:1564-1573, 2005

18. Sandhu $H$, Dehnen $W$, Roller $M$, et al: mRNA expression patterns in different stages of asbestosinduced carcinogenesis in rats. Carcinogenesis 21: 1023-1029, 2000

19. Vogelzang NJ, Rusthoven JJ, Symanowski J, et al: Phase III study of pemetrexed in combination with cisplatin versus cisplatin alone in patients with malignant pleural mesothelioma. J Clin Oncol 21: 2636-2644, 2003

20. Krug LM, Pass H, Rusch WW, et al: A multicenter phase II trial of neoadjuvant pemetrexed plus cisplatin (PC) followed by extrapleural pneumonectomy (EPP) and hemithoracic radiation (RT) for stage 
I-III malignant pleural mesothelioma (MPM). J Clin Oncol 25:399s, 2007 (suppl; abstr 7561)

21. Rice DC, Stevens CW, Correa AM, et al: Outcomes after extrapleural pneumonectomy and intensity-modulated radiation therapy for malignant pleural mesothelioma. Ann Thorac Surg 84:16851692, 2007; discussion 1692-1693

22. Rusch VW, Piantadosi S, Holmes EC: The role of extrapleural pneumonectomy in malignant pleural mesothelioma: A Lung Cancer Study Group trial. J Thorac Cardiovasc Surg 102:1-9, 1991

23. Sugarbaker DJ, Garcia JP, Richards WG, et al: Extrapleural pneumonectomy in the multimodality therapy of malignant pleural mesothelioma: Results in 120 consecutive patients. Ann Surg 224: 288-294, 1996, discussion 294-296

24. Jänne PA, Baldini EH: Patterns of failure following surgical resection for malignant pleural mesothelioma. Thorac Surg Clin 14:567-573, 2004

25. Sugarbaker DJ, Jaklitsch MT, Bueno R, et al: Prevention, early detection, and management of complications after 328 consecutive extrapleural pneumonectomies. J Thorac Cardiovasc Surg 128: 138-146, 2004

26. Martino D, Pass $\mathrm{H}$ : Integration of multimodality approaches in the management of malignant pleural mesothelioma. Clin Lung Cancer 5:290-298, 2004

27. Jaklitsch MT, Grondin SC, Sugarbaker DJ: Treatment of malignant mesothelioma. World J Surg 25:210-217, 2001

28. Rusch VW, Venkatraman E: The importance of surgical staging in the treatment of malignant pleural mesothelioma. J Thorac Cardiovasc Surg 111:815-825, 1996, discussion 825-826

29. Treasure $T$, Sedrakyan A: Pleural mesothelioma: Little evidence, still time to do trials. Lancet 364:1183-1185, 2004

30. Flores RM, Pass HI, Seshan VE, et al: Extrapleural pneumonectomy versus pleurectomy/decortication in the surgical management of malignant pleural mesothelioma: Results in 663 patients. J Thorac Cardiovasc Surg 135:620-626, 626 e1-3, 2008

31. Rusch VW, Rosenzweig K, Venkatraman $E_{\text {, }}$ et al: A phase II trial of surgical resection and adjuvant high-dose hemithoracic radiation for malignant pleural mesothelioma. J Thorac Cardiovasc Surg 122:788-795, 2001

32. Boutin C, Rey F, Viallat JR: Prevention of malignant seeding after invasive diagnostic procedures in patients with pleural mesothelioma: A randomized trial of local radiotherapy. Chest 108:754-758, 1995

33. O'Rourke N, Garcia JC, Paul J, et al: A randomised controlled trial of intervention site radiotherapy in malignant pleural mesothelioma. Radiother Oncol 84:18-22, 2007

34. Bydder S, Phillips M, Joseph DJ, et al: A randomised trial of single-dose radiotherapy to prevent procedure tract metastasis by malignant mesothelioma. Br J Cancer 91:9-10, 2004

35. Allen AM, Den R, Wong JS, et al: Influence of radiotherapy technique and dose on patterns of failure for mesothelioma patients after extrapleural pneumonectomy. Int J Radiat Oncol Biol Phys 68: 1366-1374, 2007

36. Ahamad A, Stevens CW, Smythe WR, et al: Intensity-modulated radiation therapy: A novel approach to the management of malignant pleural mesothelioma. Int J Radiat Oncol Biol Phys 55:768775,2003

37. Allen AM, Czerminska M, Janne PA, et al: Fatal pneumonitis associated with intensitymodulated radiation therapy for mesothelioma. Int J Radiat Oncol Biol Phys 65:640-645, 2006

38. Weder W, Kestenholz $P$, Taverna $C$, et al: Neoadjuvant chemotherapy followed by extrapleural pneumonectomy in malignant pleural mesothelioma. J Clin Oncol 22:3451-3457, 2004

39. Flores R, Krug L, Rosenzweig K, et al: Induction chemotherapy, extrapleural pneumonectomy, and postoperative high-dose radiotherapy for locally advanced malignant pleural mesothelioma: a phase II trial. J Thorac Oncol 1:289-295, 2006

40. Weder W, Stahel R, Bernhard J, et al: Multicenter trial of neo-adjuvant chemotherapy followed by extrapleural pneumonectomy in malignant pleural mesothelioma. Ann Oncol 18:1196-1202, 2007

41. Rea F, Marulli G, Bortolotti L, et al: Induction chemotherapy, extrapleural pneumonectomy (EPP) and adjuvant hemi-thoracic radiation in malignant pleural mesothelioma (MPM): Feasibility and results. Lung Cancer 57:89-95, 2007

42. Sugarbaker DJ, Flores RM, Jaklitsch MT, et al: Resection margins, extrapleural nodal status, and cell type determine postoperative long-term survival in trimodality therapy of malignant pleural mesothelioma: Results in 183 patients. J Thorac Cardiovasc Surg 117:54-63, 1999; discussion 63-65

43. Sugarbaker D, Richards WG, Alsup CA, et al: Impact of pathological staging on survival in patients with epithelial mesothelioma treated with extrapleural pneumonectomy. J Clin Oncol 25:435s, 2007 (suppl; abstr 7706)

44. Curran D, Sahmoud T, Therasse $P$, et al: Prognostic factors in patients with pleural mesothelioma: The European Organization for Research and Treatment of Cancer experience. J Clin Oncol 16: 145-152, 1998

45. Herndon JE, Green MR, Chahinian AP, et al: Factors predictive of survival among 337 patients with mesothelioma treated between 1984 and 1994 by the Cancer and Leukemia Group B. Chest 113: 723-731, 1998

46. Nowak AK: CT, RECIST, and malignant pleural mesothelioma. Lung Cancer 49:S37-S40, 2005 (suppl 1)

47. Byrne MJ, Nowak AK: Modified RECIST criteria for assessment of response in malignant pleural mesothelioma. Ann Oncol 15:257-260, 2004

48. van Klaveren RJ, Aerts JG, de Bruin $H$, et al: Inadequacy of the RECIST criteria for response evaluation in patients with malignant pleural mesothelioma. Lung Cancer 43:63-69, 2004

49. Francart J, Legrand C, Sylvester R, et al: Progression-free survival rate as primary end point for phase II cancer clinical trials: Application to mesothelioma-The EORTC Lung Cancer Group. J Clin Oncol 24:3007-3012, 2006

50. Ong ST, Vogelzang NJ: Chemotherapy in malignant pleural mesothelioma: A review. J Clin Oncol 14:1007-1017, 1996

51. Ellis P, Davies AM, Evans WK, et al: The use of chemotherapy in patients with advanced malignant pleural mesothelioma: A systematic review and practice guideline. J Thorac Oncol 1:591-601, 2006

52. Muers MF, Stephens RJ, Fisher $P$, et al: Active symptom control with or without chemotherapy in the treatment of patients with malignant pleural mesothelioma (MS01): A multicentre randomised trial. Lancet 371:1685-1694, 2008

53. van Meerbeeck JP, Gaafar R, Manegold C, et al: Randomized phase III study of cisplatin with or without raltitrexed in patients with malignant pleural mesothelioma: An intergroup study of the European Organisation for Research and Treatment of Cancer Lung Cancer Group and the National Cancer Institute of Canada. J Clin Oncol 23:6881-6889, 2005

54. Berghmans $T$, Paesmans $M$, Lalami $Y$, et al: Activity of chemotherapy and immunotherapy on malignant mesothelioma: A systematic review of the literature with meta-analysis. Lung Cancer 38: 111-121, 2002

55. Fennell DA, Gaudino G, O'Byrne KJ, et al: Advances in the systemic therapy of malignant pleural mesothelioma. Nat Clin Pract Oncol 5:136147, 2008

56. Ceresoli GL, Zucali PA, Favaretto AG, et al: Phase II study of pemetrexed plus carboplatin in malignant pleural mesothelioma. J Clin Oncol 24: 1443-1448, 2006

57. Castagneto B, Botta M, Aitini E, et al: Phase II study of pemetrexed in combination with carboplatin in patients with malignant pleural mesothelioma (MPM). Ann Oncol 19:370-373, 2008

58. Gralla R, Hollen $P$, Liepa $A$, et al: Improving quality of life in patients with malignant pleural mesothelioma: Results of the randomized pemetrexed + cisplatin vs cisplatin trial using the LCSSmeso instrument. Proc Am Soc Clin Oncol 22:621a, 2003 (abstr 2496)

59. Bruno C, Luca C, Manlio M, et al: Pemetrexed (MTA) and carboplatin (CBDCA) in advanced pleural mesothelioma (MPM): Evaluation of the activity and toxicity in a series of 178 chemonaive patients. Lung Cancer 54:S48, 2006 (suppl)

60. Papi M, Genestreti G, Tassinari D, et al: Pemetrexed in combination with carboplatin for the treatment of patients with malignant mesothelioma. Lung Cancer 54:S49, 2006 (suppl)

61. Santoro A, O'Brien ME, Stahel RA, et al: Pemetrexed plus cisplatin or pemetrexed plus carboplatin for chemonaive patients with malignant pleural mesothelioma: Results of the International Expanded Access Program. J Thorac Oncol 3:756763, 2008

62. Taylor P, Castagneto B, Dark G, et al: Singleagent pemetrexed for chemonaive and pretreated patients with malignant pleural mesothelioma: Results of an International Expanded Access Program. J Thorac Oncol 3:764-771, 2008

63. van den Bogaert DP, Pouw EM, van Wijhe G, et al: Pemetrexed maintenance therapy in patients with malignant pleural mesothelioma. J Thorac Oncol 1:25-30, 2006

64. Janne PA: Chemotherapy for malignant pleural mesothelioma. Clin Lung Cancer 5:98-106, 2003

65. Castagneto B, Zai S, Dongiovanni D, et al: Cisplatin and gemcitabine in malignant pleural mesothelioma: A phase II study. Am J Clin Oncol 28:223-226, 2005

66. Kalmadi SR, Rankin C, Kraut MJ, et al: Gemcitabine and cisplatin in unresectable malignant mesothelioma of the pleura: A phase II study of the Southwest Oncology Group (SWOG 9810). Lung Cancer 60:259-263, 2008

67. Byrne MJ, Davidson JA, Musk AW, et al: Cisplatin and gemcitabine treatment for malignant mesothelioma: A phase II study. J Clin Oncol 17:2530, 1999 
68. Nowak AK, Byrne MJ, Williamson R, et al: A multicentre phase II study of cisplatin and gemcitabine for malignant mesothelioma. $\mathrm{Br} J$ Cancer 87:491-496, 2002

69. van Haarst JM, Baas P, Manegold C, et al: Multicentre phase II study of gemcitabine and cisplatin in malignant pleural mesothelioma. $\mathrm{Br} \mathrm{J}$ Cancer 86:342-345, 2002

70. Favaretto AG, Aversa SM, Paccagnella A, et al: Gemcitabine combined with carboplatin in patients with malignant pleural mesothelioma: A multicentric phase II study. Cancer 97:2791-2797, 2003

71. Lee $\mathrm{C}$, Murray $\mathrm{N}$, Anderson $\mathrm{H}$, et al: Outcomes with platinum plus gemcitabine or pemetrexed as first-line systemic therapy for malignant pleural mesothelioma in British Columbia: A review of province-wide practice. J Thorac Oncol 2:606, 2007 (suppl 4; abstr P1-140)

72. Jänne PA, Simon GR, Langer CJ, et al: Phase II trial of pemetrexed and gemcitabine in chemotherapynaive malignant pleural mesothelioma. J Clin Oncol 26:1465-1471, 2008

73. Steele JP, Shamash J, Evans MT, et al: Phase II study of vinorelbine in patients with malignant pleural mesothelioma. J Clin Oncol 18:39123917, 2000

74. Sørensen JB, Frank $H$, Palshof $T$ : Cisplatin and vinorelbine first-line chemotherapy in nonresectable malignant pleural mesothelioma. $\mathrm{Br} J$ Cancer 99:44-50, 2008

75. Talbot DC, Margery J, Dabouis G, et al: Phase II study of vinflunine in malignant pleural mesothelioma. J Clin Oncol 25:4751-4756, 2007

76. Nakano T, Fukuoka K, Kuribayashi $K$, et al: Sequential topoisomerase targeting triplet chemotherapy with irinotecan/cisplatin followed by doxorubicin in patients with malignant pleural mesothelioma: A pilot phase II study. Lung Cancer 54:S48, 2006 (suppl)

77. Kuribayashi K, Fukuoka K, Miyake M, et al: Combination chemotherapy with methotrexate, irinotecan, and doxorubicin in malignant pleural mesothelioma: A phase II study. Lung Cancer 54:S49, 2006 (suppl)

78. Kindler $\mathrm{H}$, Herndon J, Zhang $\mathrm{C}$, et al: Irinotecan for malignant mesothelioma: A Phase II trial by the Cancer and Leukemia Group B. Lung Cancer 48:423-428, 2005

79. Sorensen J, Sundstrom S, Perell K, et al: Pemetrexed second-line treatment in malignant pleural mesothelioma following platinum-based first-line treatment. Lung Cancer 54:S46, 2006 (suppl)

80. Jänne PA, Wozniak AJ, Belani $C P$, et al: Pemetrexed alone or in combination with cisplatin in previously treated malignant pleural mesothelioma: Outcomes from a phase IIIB expanded access program. J Thorac Oncol 1:506-512, 2006

81. Jassem J, Ramlau R, Santoro A, et al: Phase III trial of pemetrexed plus best supportive care compared with best supportive care in previously treated patients with advanced malignant pleural mesothelioma. J Clin Oncol 26:1698-1704, 2008

82. Zucali P, Garassino I, Ceresoli G, et al: Treatment with gemcitabine and vinorelbine (GEMVIN) as second-line chemotherapy in pemetrexed-pretreated patients with malignant pleural mesothelioma. Lung Cancer 54:S48, 2006 (suppl)

83. Stebbing J, Powles T, McPherson K, et al: The efficacy and safety of weekly vinorelbine in relapsed malignant pleural mesothelioma. Lung Cancer 63:94-97, 2009

84. Govindan R, Kratzke RA, Herndon JE II, et al: Gefitinib in patients with malignant mesothelioma: A phase II study by the Cancer and Leukemia Group B. Clin Cancer Res 11:2300-2304, 2005

85. Garland LL, Rankin C, Gandara DR, et al: Phase II study of erlotinib in patients with malignant pleural mesothelioma: A Southwest Oncology Group Study. J Clin Oncol 25:2406-2413, 2007

86. Mathy A, Baas $P$, Dalesio $O$, et al: Limited efficacy of imatinib mesylate in malignant mesothelioma: A phase II trial. Lung Cancer 50:83-86, 2005

87. Porta C, Mutti L, Tassi G: Negative results of an Italian Group for Mesothelioma (G.I. Me.) pilot study of single-agent imatinib mesylate in malignant pleural mesothelioma. Cancer Chemother Pharmacol 59:149-150, 2007

88. Millward M, Parnis F, Byrne $M$, et al: Phase II trial of imatinib mesylate in patients with advanced pleural mesothelioma. Proc Am Soc Clin Oncol 22:228a, 2003 (abstr 912)

89. Karrison $\mathrm{T}$, Kindler $\mathrm{HL}$, Gandara DR, et al: Final analysis of a multi-center, double-blind, placebo-controlled, randomized phase II trial of gemcitabine/cisplatin (GC) plus bevacizumab (B) or placebo $(P)$ in patients (pts) with malignant mesothelioma (MM). J Clin Oncol 25:391s, 2007 (suppl; abstr 7526)

90. Dowell JE, Kindler HL: Antiangiogenic therapies for mesothelioma. Hematol Oncol Clin North Am 19:1137-1145, 2005, viii

91. Kindler $H$, Vogelzang $J$, Chien $K$, et al: SU5416 in malignant mesothelioma: A University of Chicago Phase II Consortium Study. Proc Am Soc Clin Oncol 20:1359a, 2001 (abstr 1359)

92. Pavlakis N, Williams G, Harvey $R$, et al: Thalidomide alone and in combination with cisplatin/ gemcitabine chemotherapy for malignant mesothelioma (MM): preliminary results from two phase II studies. Proc Am Soc Clin Oncol 21:19b, 2002 (abstr 1885)

93. Baas $P$, Boogerd W, Dalesio $O$, et al: Thalidomide in patients with malignant pleural mesothelioma. Lung Cancer 48:291-296, 2005

94. Jahan TM, Gu L, Wang $X$, et al: Vatalanib (V) for patients with previously untreated advanced malignant mesothelioma (MM): A phase II study by the Cancer and Leukemia Group B (CALGB 30107). J Clin Oncol 24:384s, 2006 (suppl; abstr 7081)

95. Janne PA, Wang XF, Krug LM, et al: Sorafenib in malignant mesothelioma (MM): A phase II trial of the Cancer and Leukemia Group (CALGB 30307). J Clin Oncol 25:435s, 2007 (suppl; abstr 7707)

96. Nowak AK, Millward MJ, Francis R, et al: Phase II study of sunitinib as second-line therapy in malignant pleural mesothelioma (MPM). J Clin Oncol 26:439s, 2008 (suppl; abstr 8063)

97. Mikulski SM, Costanzi JJ, Vogelzang NJ, et al: Phase II trial of a single weekly intravenous dose of ranpirnase in patients with unresectable malignant mesothelioma. J Clin Oncol 20:274-281, 2002

98. Vogelzang N, Taub R, Shin D, et al: Phase III randomized trial of onconase (ONC) vs. doxorubicin (DOX) in patients (Pts) with unresectable malignant mesothelioma (UMM): Analysis of survival. Proc Am Soc Clin Oncol 19:577a, 2000 (abstr 2274)

99. Pavlakis N, Vogelzang NJ: Ranpirnase: An antitumour ribonuclease-Its potential role in malig- nant mesothelioma. Expert Opin Biol Ther 6:391399, 2006

100. Krug LM, Curley T, Schwartz L, et al: Potential role of histone deacetylase inhibitors in mesothelioma: Clinical experience with suberoylanilide hydroxamic acid. Clin Lung Cancer 7:257-261, 2006

101. König JE, Tolnay $E$, Wiethege $T$, et al: Expression of vascular endothelial growth factor in diffuse malignant pleural mesothelioma. Virchows Arch 435:8-12, 1999

102. Jackman DM, Kindler HL, Yeap BY, et al: Erlotinib plus bevacizumab in previously treated patients with malignant pleural mesothelioma. Cancer 113:808-814, 2008

103. Janne $P$, Wang $X$, Krug $L$, et al: Phase II trial of sorafenib (BAY) 43-9006) in malignant mesothelioma: CALGB 30307. Lung Cancer 54:S51, 2006 (suppl)

104. Ali $Y$, Lin $Y$, Gharibo $M M$, et al: Phase and pharmacokinetic study of imatinib mesylate (Gleevec) and gemcitabine in patients with refractory solid tumors. Clin Cancer Res 13:5876-5882, 2007

105. Bertino P, Piccardi F, Porta C, et al: Imatinib mesylate enhances therapeutic effects of gemcitabine in human malignant mesothelioma xenografts. Clin Cancer Res 14:541-548, 2008

106. Von Pawel J, Costanzi J, Hardiman S: A comparison of CALGB and EORTC paradigms in the assessment of ONCONASE for the treatment of unresectable malignant mesothelioma (UMM). Lung Cancer 54:S51, 2006 (suppl)

107. Fennell DA, Parmar A, Shamash J, et al: Statistical validation of the EORTC prognostic model for malignant pleural mesothelioma based on three consecutive phase II trials. J Clin Oncol 23:184-189, 2005

108. Cao XX, Mohuiddin I, Ece F, et al: Histone deacetylase inhibitor downregulation of bcl-xl gene expression leads to apoptotic cell death in mesothelioma. Am J Respir Cell Mol Biol 25:562-568, 2001

109. Sonnemann J, Hartwig M, Plath $A$, et al: Histone deacetylase inhibitors require caspase activity to induce apoptosis in lung and prostate carcinoma cells. Cancer Lett 232:148-160, 2006

110. Kim TY, Bang YJ, Robertson KD: Histone deacetylase inhibitors for cancer therapy. Epigenetics 1:14-23, 2006

111. Fennell D, Gaudino G, Porta C, et al: Proteasome inhibitors for treatment of malignant mesothelioma. Lung Cancer 54:S50, 2006 (suppl)

112. Gordon G, Mani M, Maulik G, et al: Preclincial studies of the protesome inhibtor bortezomib (velcade) in malignant pleural mesothelioma (MPM). Lung Cancer 54:S50, 2006 (suppl)

113. Molnar-Kimber $K L$, Sterman $D H$, Chang $M$, et al: Impact of preexisting and induced humoral and cellular immune responses in an adenovirusbased gene therapy phase I clinical trial for localized mesothelioma. Hum Gene Ther 9:2121-2133, 1998

114. Sterman DH, Kaiser LR, Albelda SM: Gene therapy for malignant pleural mesothelioma. Hematol Oncol Clin North Am 12:553-568, 1998

115. Sterman $D H$, Recio $A$, Carroll $R G$, et al: $A$ phase I clinical trial of single-dose intrapleural IFNbeta gene transfer for malignant pleural mesothelioma and metastatic pleural effusions: High rate of antitumor immune responses. Clin Cancer Res 13: 4456-4466, 2007

116. Sterman DH, Treat J, Litzky LA, et al: Adenovirus-mediated herpes simplex virus thymidine kinase/ganciclovir gene therapy in patients with 
localized malignancy: Results of a phase I clinical trial in malignant mesothelioma. Hum Gene Ther 9:1083-1092, 1998

117. Sterman $D H$, Recio $A$, Vachani $A$, et al: Long-term follow-up of patients with malignant pleural mesothelioma receiving high-dose adenovirus herpes simplex thymidine kinase/ganciclovir suicide gene therapy. Clin Cancer Res 11:7444-7453, 2005

118. Tsao AS, He D, Saigal $B$, et al: Inhibition of c-Src expression and activation in malignant pleura mesothelioma tissues leads to apoptosis, cell cycle arrest, and decreased migration and invasion. Mol Cancer Ther 6:1962-1972, 2007

119. Hassan R, Bera $T$, Pastan I: Mesothelin: A new target for immunotherapy. Clin Cancer Res 10:3937-3942, 2004

120. Hassan R, Ho M: Mesothelin targeted cancer immunotherapy. Eur J Cancer 44:46-53, 2008

121. Kratzke R: IGF pathway activation in mesothelioma. Lung Cancer 54:S54, 2006 (suppl)

122. Jacobson $B$, Patel $M$, De A, et al: Activation of 4E-BP1 represses IGF-1 mediated cap-dependent traslation in malignant pleural mesothelioma. Lung Cancer 54:S55, 2006 (suppl)

123. Miraki-Mound F, Martinelli C, CamachoHubner C: Effects of insulin-like growth factor binding protein-3 on human malignant pleural mesothelioma cell growth and apoptosis. Lung Cancer 54:S53, 2006 (suppl)

124. Brown AB, Krug LM, Maslak $P$, et al: Pilot trial of a Wilms tumor-1 (WT-1) peptide vaccine in patients with thoracic and myeloid neoplasms. J Clin Oncol 26:144s, 2008 (suppl; abstr 3051) 